Colin Harlingten

Site 81C, Comp 2, RR1

Okanagan Falls

BC

VOH 1R0

Ms. Erica Hamilton

Commission Secretary

B.C. Utilities Commission

900 Howe Street, Box 250

Vancouver, BC V6Z 2N3

May 20th, 2008

Dear Ms. Hamilton,

Re: FortisBC Certificate of Public Convenience and Necessity for the Okanagan Transmission Reinforcement Project ("OTR Project') Project No. 3698488

Please accept the attachments as a submission into subject hearing as Evidence \# $\mathbf{2 3}$ for future reference in subject hearing.

BEMS,WHO, and the Precautionary Principle - Blank \& Goodman

I cite

The WHO EMF program would do well to acknowledge recent biological research and promote forward looking policies in the spirit of the Precautionary Principle, rather than continue to insist that the status quo is just fine. Our environment is changing rapidly, both in the power frequency range, but especially in the growing $R F$ background from radio, TV, and cell phone transmission. At a minimum, the WHO should incorporate recent scientific advances into its policies and support the inclusion of nonthermal effects in risk assessment. The WHO should also support safety standards that take into account the cumulative effects of EMF exposures across the spectrum

Yours truly,

Colin Harlingten 


\title{
Comment
}

\section{BEMS, WHO, and the Precautionary Principle}

\author{
Martin Blank ${ }^{1 *}$ and Reba Goodman ${ }^{2}$ \\ ${ }^{1}$ Department of Physiology, Columbia University, New York \\ ${ }^{2}$ Department of Pathology, Columbia University, New York
}

The recent Bioelectromagnetics Supplement [BEMS, 2005], based on a symposium organized by the World Health Organization (WHO), must have been approved by the BEMS Board, but was not in our Society's best interest. The supplement was designed by WHO to promote the WHO electromagnetic fields (EMF) program, and it gave itself a good 'report card' in the introduction. We are not opposed to WHO doing that in its own publications, just not in ours. Here is a more realistic 'report card' on the Supplement and the EMF program of the WHO.

The mix of papers in the Supplement included epidemiology, dosimetry, etc., but was deficient in bioelectromagnetics mechanisms. Having chosen our Journal, one would have expected the WHO to come up with a reasonable paper on biological mechanisms. Can you imagine a review on mechanism of interaction with biological tissue [Challis, 2005] that does not include the latest studies on interaction of RF with DNA? A recurring theme of the symposium was the possibility of cancer, and cancer was clearly linked to DNA in the good review by Lightfoot [2005]. Why not include ELF mechanisms, since cellphones include both ELF and $\mathrm{RF}$, and both activate the same biological mechanisms [Blank and Goodman, 2004]? Why publish the symposium at all, if we could not review the quality of the papers and pick the referees to insure that the papers would meet BEMS standards? The disclaimer by the Editor at the beginning of the issue is meaningless! Publication of a paper with our imprimatur lends credibility to the WHO program, where a sincere interest in meaningful research into disease related mechanisms involving EMF is painfully absent.

That last remark may appear unusually harsh, but how else can one describe the failure of the WHO symposium to mention the many research papers showing stimulation of DNA as in the stress response [e.g., Leszczinski et al., 2004], reports of DNA strand breaks [e.g., Lai and Singh, 2004; REFLEX Project Report, 2004], and the 'Liburdy experiment' [Liburdy, 2003] showing a loss of inhibition of breast cancer cell growth by melatonin/tamoxifen, all due to EMF and all replicated in many laboratories? The references given here cite many related papers.

Another reason for this harsh judgment is the WHO policy regarding the Precautionary Principle. The Precautionary Principle defines a proactive policy for regulatory agencies when information about risk is inconclusive, but where there is a reasonable possibility that the public may be harmed if no action is taken. The 1992 Treaty on European Union favored the Precautionary Principle, and it has been invoked by Italy and Switzerland to regulate RF levels. Initially, the WHO EMF program appeared to support the idea, but then reversed its policy. Why?

Opposing the Precautionary Principle is almost like opposing Motherhood. It is good old fashioned common sense, and its soundness is embodied in the conventional wisdom of many popular sayings:

- 'Better safe than sorry.'

- 'An ounce of prevention is worth a pound of cure.'

- It is easier to stay out of trouble, than to get out of trouble.'

In the bioelectromagnetics community, we see it as closely related to 'Prudent Avoidance,' the unofficial practical advice given to individuals about how to deal with EMF. As if that were not enough, it sounds a lot like the legal concept of the 'reasonable man,' and how he would be expected to behave under such circumstances. Even if one

*Correspondence to: Martin Blank, Department of Physiology, Columbia University, 630 West 168 Street, New York, NY 10032. E-mail: mb32@columbia.edu

Received for review 27 January 2006; revision received 6 February 2006

DOI 10.1002/bem.20261

Published online in Wiley InterScience

(www.interscience.wiley.com). 
is opposed to Motherhood, the Precautionary Principle can be interpreted in different ways, so one would think that WHO would support this policy, if only for public relations.

The WHO EMF program would do well to acknowledge recent biological research and promote forward looking policies in the spirit of the Precautionary Principle, rather than continue to insist that the status quo is just fine. Our environment is changing rapidly, both in the power frequency range, but especially in the growing RF background from radio, $\mathrm{TV}$, and cell phone transmission. At a minimum, the WHO should incorporate recent scientific advances into its policies and support the inclusion of nonthermal effects in risk assessment. The WHO should also support safety standards that take into account the cumulative effects of EMF exposures across the spectrum.

The take home message for BEMS is to exert better editorial control over all our publications, so that scientific standards are maintained and we are not used to promote the agendas of other groups.

\section{REFERENCES}

BEMS. 2005. Proceedings of WHO-sponsored symposium on "Sensitivity of Children to EMF Exposure". Bioelectromagnetics Suppl 7:S1-S160.

Blank M, Goodman R. 2004. A biological standard for electromagnetic safety: The stress response. Bioelectromagnetics 25:642-646.

Challis LJ. 2005. Mechanisms for interaction between RF fields and biological tissue. Bioelectromagnetics Suppl 7:S98-S106.

Lai H, Singh NP. 2004. Magnetic field induced strand breaks in brain cells of the rat. Environ Health Perspect 112(6):687-694.

Leszczinski D, Nylund R, Joevaara S, Reivinen J. 2004. Applicability of discovery science approach to determine biological effects of mobile phone radiation. Proteonomics 4: $426-431$.

Liburdy R. 2003. Electromagnetic fields and control of cell growth. Drugs, hormones, and human tumor cells: A summary of replication studies at five laboratories. In: McLean MJ, Engstrom S, Holcomb RR, editors. Magnetotherapy: Potential therapeutic benefits and adverse effects. New York: TGF Press, 2003. pp 57-88.

Lightfoot T. 2005. Aetiology of childhood leukemia. Bioelectromagnetics Suppl 7:S51-S59.

REFLEX Project Report. 2004. http://www.verum-foundation. de/www2004/html/pdf/cuprojekte01/REFLEX_ProgressSummary_231104.pdf [accessed August 2006]. 